\title{
Circularly Polarized Triband Printed Quasi-Yagi Antenna for Millimeter-Wave Applications
}

\author{
Dalia M. Elsheakh ${ }^{1}$ and Magdy F. Iskander ${ }^{2}$ \\ ${ }^{1}$ Microstrip Department, Electronics Research Institute, Cairo 21622, Egypt \\ ${ }^{2}$ Hawaii Center for Advanced Communications (HCAC), Honolulu, HI 96822, USA \\ Correspondence should be addressed to Dalia M. Elsheakh; daliaelsheakh@gmail.com
}

Received 30 October 2014; Revised 21 January 2015; Accepted 25 January 2015

Academic Editor: Atsushi Mase

Copyright (c) 2015 D. M. Elsheakh and M. F. Iskander. This is an open access article distributed under the Creative Commons Attribution License, which permits unrestricted use, distribution, and reproduction in any medium, provided the original work is properly cited.

\begin{abstract}
This paper describes the design and development of a triband with circularly polarized quasi-Yagi antenna for ka-band and short range wireless communications applications. The proposed antenna consists of an integrated balun-fed printed dipole, parasitic folded dipole and a short strip, and a modified ground plane. The antenna structure, together with the parasitic elements, is designed to achieve circular polarization and triband operating at resonant frequencies of $13.5 \mathrm{GHz}, 30 \mathrm{GHz}$, and $60 \mathrm{GHz}$. Antenna design was first simulated using HFSS ver.14, and the obtained results were compared with experimental measurements on a prototype developed on a single printed circuit board. Achieved characteristics include $-10 \mathrm{~dB}$ impedance bandwidth at the desired bands, circular polarization axial ratio $A R<3 \mathrm{~dB}$, front to back ratio of $6 \mathrm{~dB}$, gain value of about $4 \mathrm{dBi}$, and average radiation efficiency of $60 \%$. The paper includes comparison between simulation and experimental results.
\end{abstract}

\section{Introduction}

Recently printed antennas have been commonly used in sensing and various communications and radar systems applications due to their low cost, low profile, and simple integration with transceiver systems. For example, microstrip arrays are highly desired for the broadcast satellite services (BSS) in the frequency band at $13.5 \mathrm{GHz}$ [1]. Moreover, the unlicensed frequency bands in the $30 \mathrm{GHz}$ and $60 \mathrm{GHz}$ ranges are used for increased data rate of more than $1 \mathrm{~Gb} / \mathrm{s}$ in WLAN (wireless local area network IEEE 802.11n) and WPAN (wireless personal area network) short range communication systems [2].

Some examples of printed antenna implementations illustrate specific and interesting particular solutions and show that they can be integrated with solid-state devices [3-5]. Of specific interest in this paper are those designs that are based on new shapes of Yagi-antenna implementation. Yagi-type antennas have several advantages over many other commonly used ones in portable communication systems [5-7]. First, the presence of the substrate provides mechanical support for the antenna and planar transmission line compatibility. Second, the parasitic director element on the top plane simultaneously directs the antenna propagation towards the endfire direction and acts as an impedance-matching parasitic element as well [8].

Development of antennas with circular polarization (CP) radiation patterns is also desirable in satellite communications systems and for portable wireless communications systems as they reduce multipath fading effects and provide flexibility in the orientation angles between transmitters and receivers. However, $\mathrm{CP}$ antennas reduce efficiency compared to linearly polarized antennas $[7,9]$. Many $\mathrm{CP}$ antennas also have complex feeding networks and configurations and hence increase packaging cost and system sizes [10]. Nonetheless, various integrated $\mathrm{CP}$ antenna designs have been proposed for MM-wave applications and these designs were implemented in either multilayer or one-layer solutions [11].

Development of antennas with multiband radiation characteristics is yet another desirable and important feature. Various techniques of printed MM-wave antenna for dual band and circular polarization have been reported [12]. These 


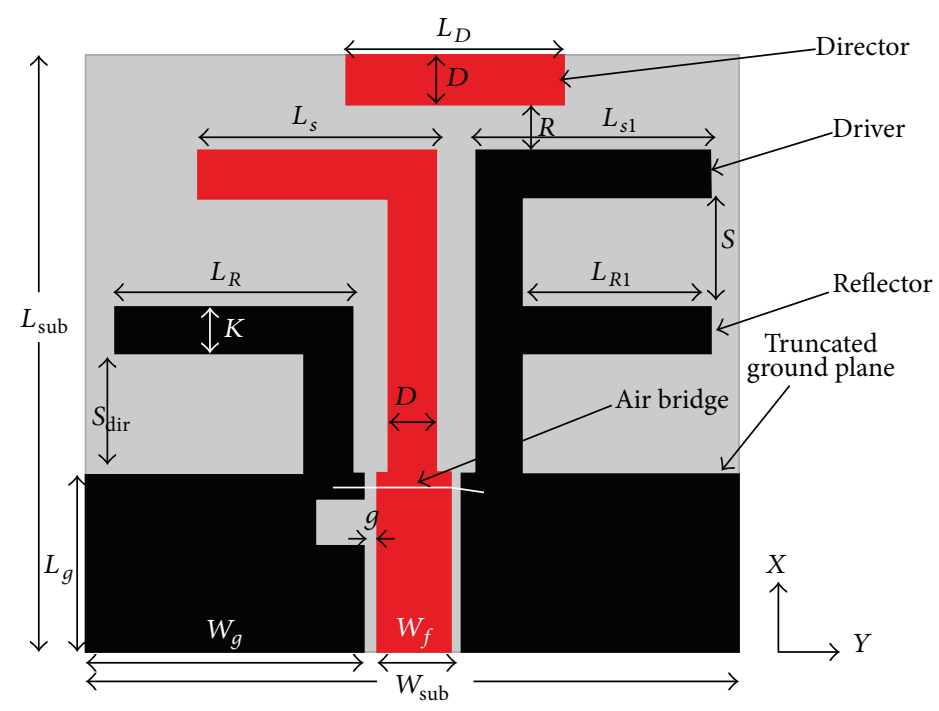

FIGURE 1: The proposed quasi-Yagi antenna configuration.

designs, however, have not been widely used due to several undesirable features, including narrow band, small axial ratio, and relatively complex structures and heavier weights.

The main objective of this paper is to describe the design of a low cost, simple structure, multiband quasi-Yagi antenna with circular polarization radiation pattern. The rest of the paper is organized as follows: in Section 2, the design and simulation of the quasi-Yagi antenna are described. Section 3 discusses the experimental measurements and results. Section 4 concludes and summarizes features and characteristics of the designed antenna.

\section{Antenna Design and Simulation}

As mentioned earlier, printed quasi-Yagi antenna is widely used in communication and radar applications due to its high directivity, high radiation efficiency, low profile, and ease of fabrication. It has, however, narrow bandwidth, and this is considered its main disadvantage. Aimed at increasing the bandwidth of planar printed quasi-Yagi antennas, many designs have been reported [8]. In this paper, a hybrid Tdipole and quasi-Yagi antenna have been used to achieve broadband as shown in Figure 1.

In this case, the quasi-Yagi antenna consists of a ground plane that acts as a reflector with width $W_{g}$ and length $L_{g}$, T-shaped printed dipole with length $L_{S}$ as a driven element, and the parasitic strip with length $L_{D}$ as a director which is printed at distance $R$ from the driven element of the antenna. Design method is on feeding (balun) structure to improve the impedance bandwidth [13-15]. Various design shapes in developing this antenna, shown in Figures 2(a)-2(c), have been studied and obtained. $\left|S_{11}\right|$ results for each of these cases are shown in Figure 2(d). First, the response of the folded dipole CPW-fed shown in Figure 2(a) was simulated and $\left|S_{11}\right|$ results are shown as blue dashed line in Figure 2(d).
TABLE 1: Optimized proposed antenna dimensions ( $\mathrm{mm})$.

\begin{tabular}{lccccccc}
\hline$L_{\text {sub }}$ & $L_{g}$ & $L_{R}$ & $L_{S}$ & $L_{D}$ & $S_{\text {dir }}$ & $L_{S 1}$ & $W_{g}$ \\
\hline 5 & 2 & 2 & 2 & 1.8 & 1 & 2.2 & 2.2 \\
\hline$W_{\text {sub }}$ & $W_{f}$ & $g$ & $S$ & $D$ & $K$ & $L_{R 1}$ & $R$ \\
\hline 5 & 0.62 & 0.1 & 0.9 & 0.4 & 0.4 & 2.15 & 0.5 \\
\hline
\end{tabular}

The director element is then introduced in Figure 2(b), and its effect on the $\left|S_{11}\right|$ performance is shown as red dashed line in Figure 2(d). To create a new resonant frequency at $13.5 \mathrm{GHz}$ and improve the antenna bandwidth at $60 \mathrm{GHz}$, a second "virtual" dipole with length $L_{R}$ which is away from the ground plane by a distance $S_{\text {dir }}$ is added to the ground plane to perform as a reflector element in the proposed Yagi design as shown in Figure 2(c). The impact of this change in the design on the overall performance of the antenna is shown as the black solid line in Figure 2(d). The air bridge (see Figure 1) is also added to keep the two ground planes at the same potential and insure the electrical balance of operation. The antenna was built on a substrate of relative dielectric constant 3.5 , loss tangent 0.0015 , and substrate thickness $0.13 \mathrm{~mm}$. The folded dipole $L_{R}$ was designed to operate at $13.5 \mathrm{GHz}$ and T-dipole was designed to radiate at $30 \mathrm{GHz}$, while the parasitic element was designed to operate at $60 \mathrm{GHz}$. The optimized dimensions of the proposed antenna to provide good impedance matching at the desired frequencies are shown in Table 1. The two dipoles are printed on one side with spacing between $S$ and $S_{\text {dir }}$. For CP operation we slightly changed the lengths $L_{S 1}$ and $L_{R 1}$ and shifted $L_{D}$ from the Tshaped center [12].

2.1. Antenna Parametric Study. The HFSS ver.14 FEM solver from Ansys is used for the design simulations. The initial design of the dipoles used $2 L_{S}, 2 L_{R}$, and $L_{D}$ at approximately 


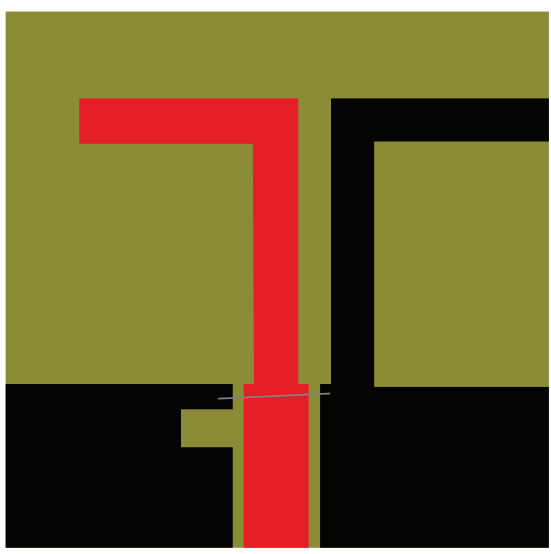

(a)

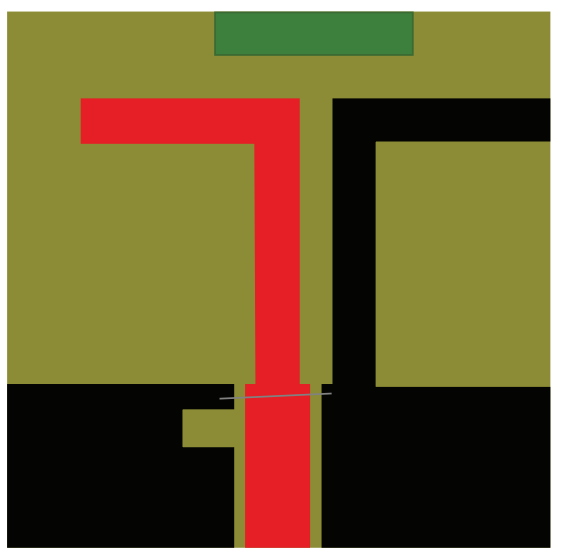

(b)

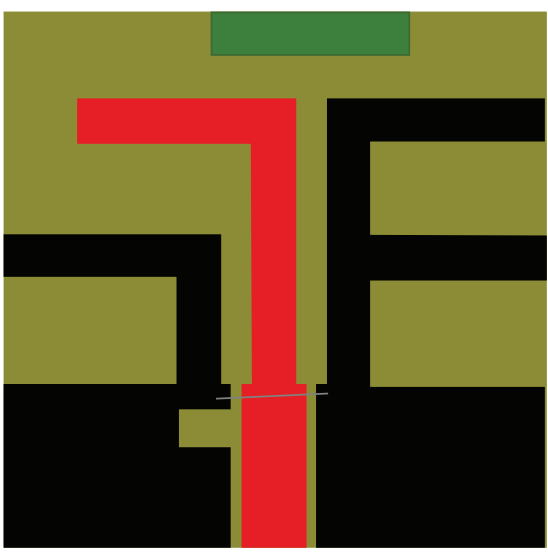

(c)

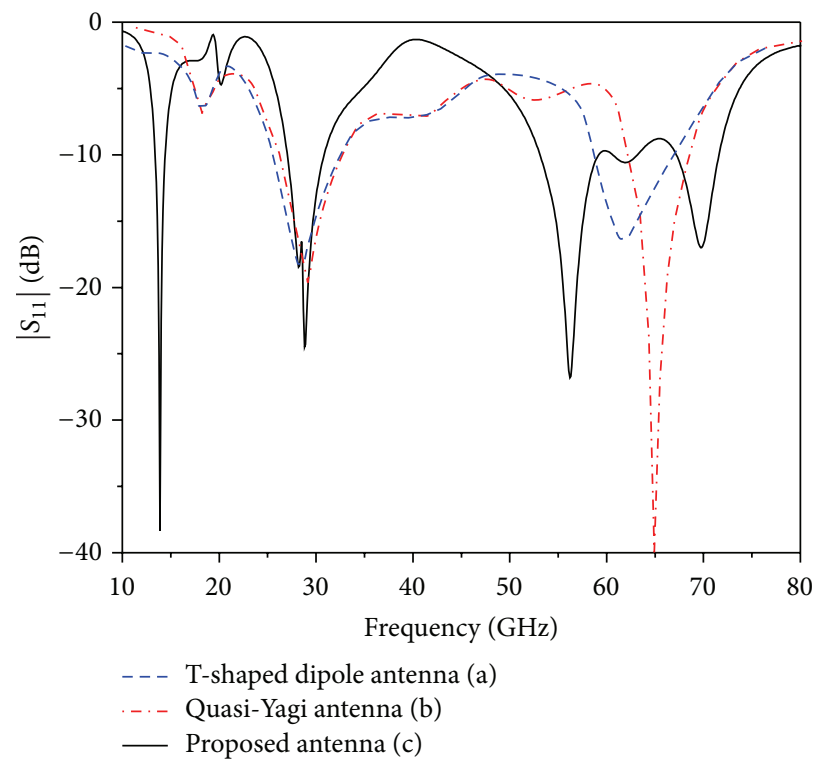

(d)

Figure 2: (a)-(c) Design steps of the proposed antenna and (d) $\left|S_{11}\right|$ result response at each step.

half of the effective wavelength $\left(\lambda_{\text {eff }} / 4\right)$ at $13.5 \mathrm{GHz}, 30 \mathrm{GHz}$, and $60 \mathrm{GHz}$, respectively. The folded virtual dipole, T-shaped dipole, and parasitic strip act as the reflector, driver, and director of the proposed antenna, respectively. The optimized dimensions of the proposed antenna so as to provide good impedance matching at the desired frequency are given in Table 1.

The unequal arms lengths are between $L_{s}, L_{s 1}$ and $L_{R}$, $L_{R 1}$, to be off center of the element axis $L_{D}$ to cause $90^{\circ}$ phase difference at $13.5 \mathrm{GHz}, 30 \mathrm{GHz}$, and $60 \mathrm{GHz}$, respectively, without using any coupler network to provide circular polarization. This could be explained as by utilizing two different lengths of monopole arms, we realize a change in the electric current phases of the arms. Particularly, the radiated field is the submission of radiation of monopole arms currents. The arm with a length shorter than at resonance frequency generates a wave with relative phase delay, whereas that with larger length generates a wave with relative phase advance. Taking advantage of this lead and lag of the antenna phases, the phase difference of 90 is tuned at this resonant frequency $[8,11,12,16-23]$.

The effects of $L_{S}, L_{R}, L_{D}$, and $S_{d}$ on the antenna performance were examined by changing one parameter at a time and keeping the other parameters fixed as shown in Figure 3.

From Figure 3(a) it may be seen that as the length of T-dipole $L_{s}$ is increased, from 1 to $3 \mathrm{~mm}$ with steps $1 \mathrm{~mm}$, the fundamental resonant frequency decreased from 16 to $12 \mathrm{GHz}$. Moreover, $L_{s}$ affects the lower resonant frequency at the higher band and reduces the resonant frequency from 56 to $53 \mathrm{GHz}$.

As for the folded dipole length $L_{R}$, simulation results show that as $L_{R}$ is increased from $1 \mathrm{~mm}$ to $2 \mathrm{~mm}$ with step 

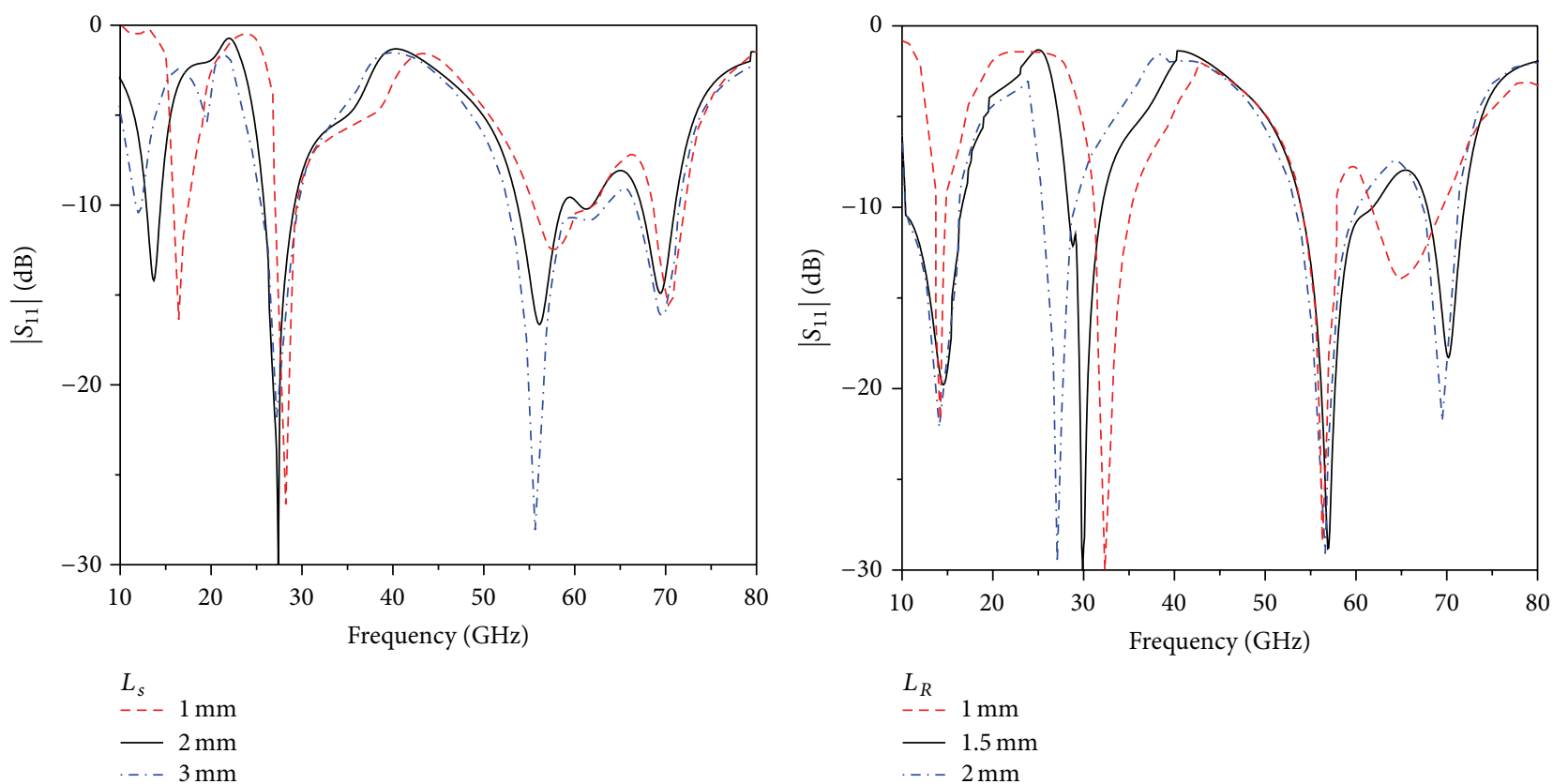

(a)

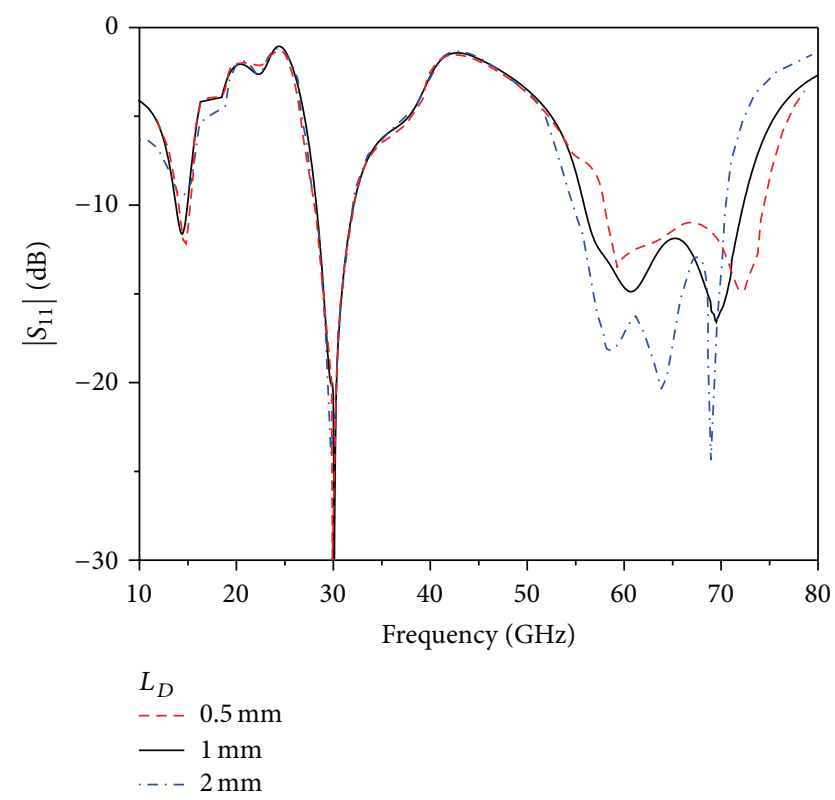

(b)

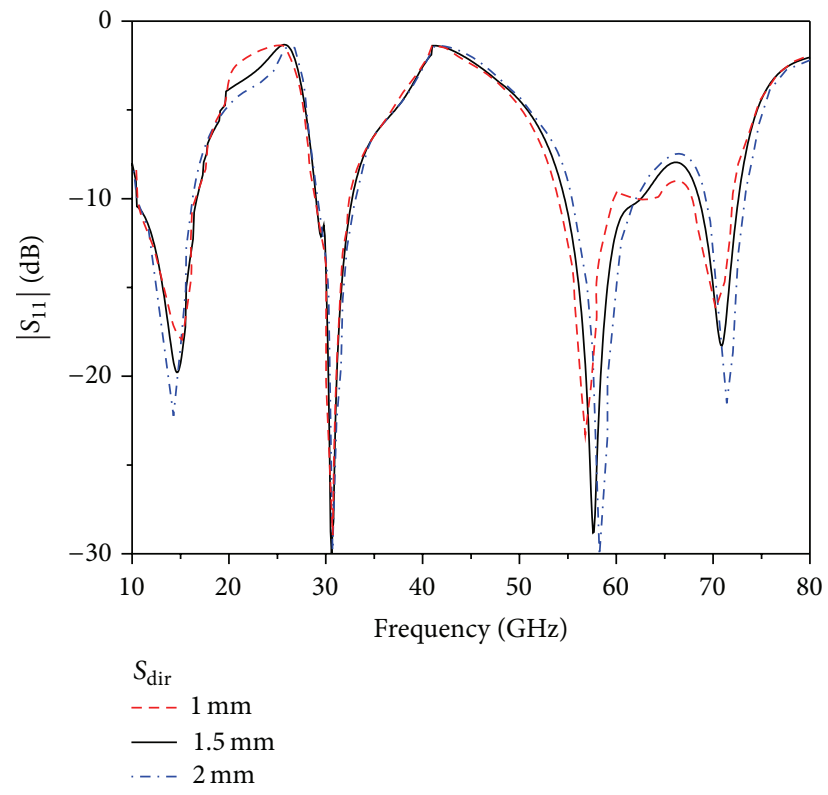

(c)

(d)

FIGURE 3: (a)-(d) $\left|S_{11}\right|$ as function of $L_{S}, L_{R}, L_{D}$, and $S_{\text {dir }}$, respectively.

$0.5 \mathrm{~mm}$, the second resonant frequency is reduced from 33 to $28 \mathrm{GHz}$ with slight effect on other resonant frequencies as shown in Figure 3(b).

The increase in the parasitic strip length $L_{D}$ from 0.5 to $2 \mathrm{~mm}$ gives rise to a reduction in the highest frequency band from $58-75 \mathrm{GHz}$ to $55-69 \mathrm{GHz}$ without affecting the other resonant frequencies as shown in Figure 3(c). Moreover, the separation between T-dipole and folded dipole $S_{\text {dir }}$ independently affects the antenna resonant frequency response as shown in Figure 3(d).

The dimensions of the optimized antenna are shown in Table 1 where the length of $L_{S 1}$ is slightly increased compared to $L_{S}$ by $0.2 \mathrm{~mm}$, the length of $L_{R 1}$ is slightly increased from that of $L_{R}$ by $0.15 \mathrm{~mm}$, and the director element $L_{D}$ is shifted 


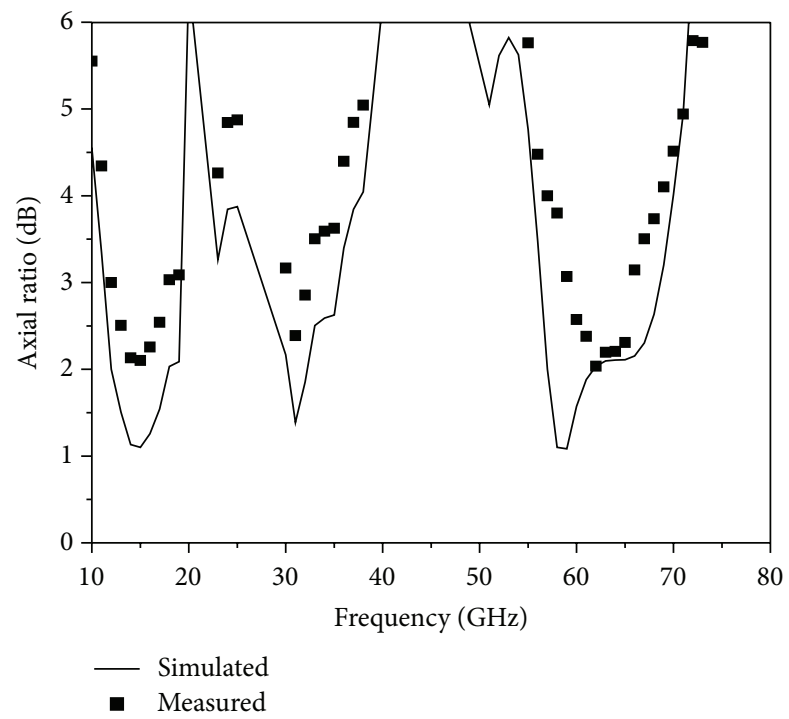

FIgURE 4: Simulated and measured axial ratio of the proposed antenna.
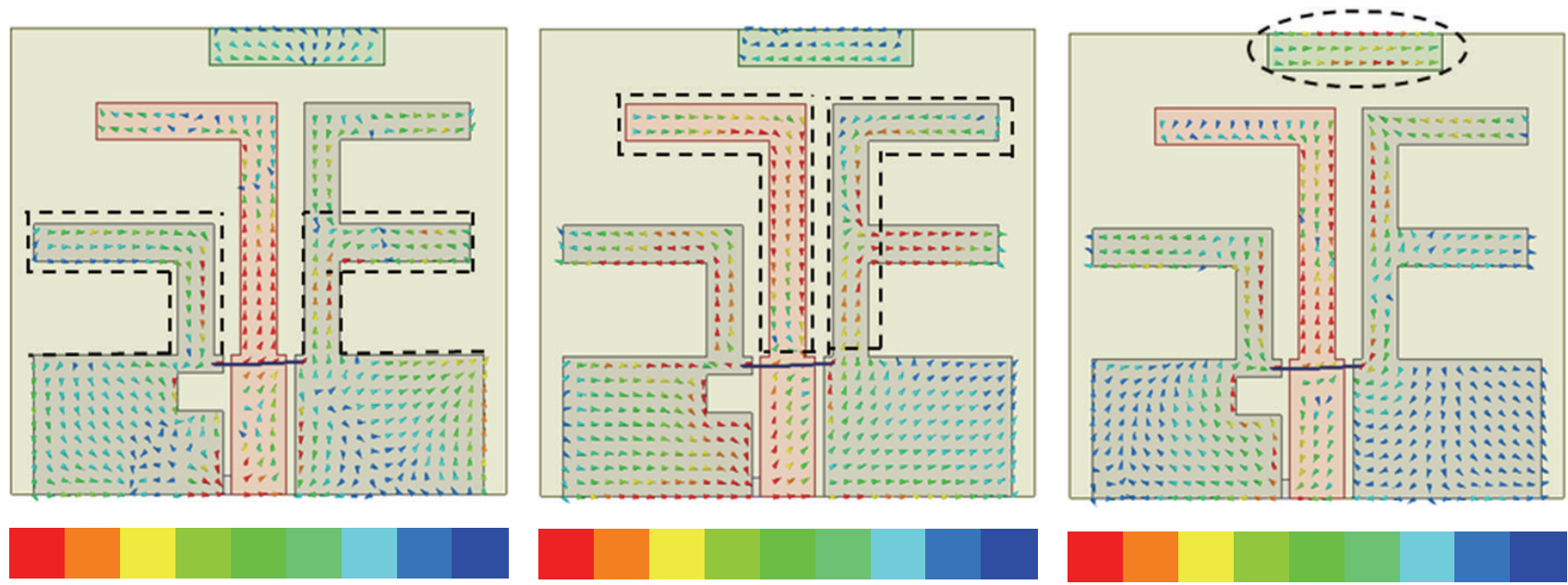

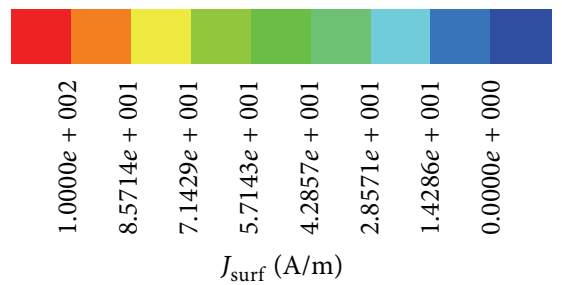

(b)

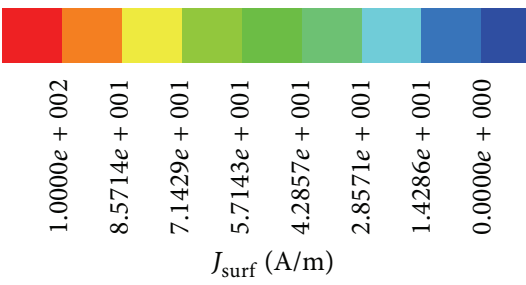

(c)

FIGURE 5: (a)-(c) The current distribution at 13.5, 30, and $60 \mathrm{GHz}$, respectively.

from the gap center of driver T-dipole by $0.5 \mathrm{~mm}$. Figure 4 compares the measured and simulated axial ratios of the proposed antenna versus frequency at the maximum gain direction. Simulated results show that the antenna has an $A R$ bandwidth of $5 \mathrm{GHz}, 6 \mathrm{GHz}$, and $12 \mathrm{GHz}$ at $13.5 \mathrm{GHz}, 30 \mathrm{GHz}$, and $60 \mathrm{GHz}$, respectively. Measurements show that the AR bandwidth is close to $4 \mathrm{GHz}$ and $8 \mathrm{GHz}$ at $13.5 \mathrm{GHz}, 30 \mathrm{GHz}$, and $60 \mathrm{GHz}$, respectively.
2.2. Antenna Performance. The performance of the proposed antenna at the three resonant frequencies was further simulated and studied. Results of the surface current distribution are shown in Figure 5 for each antenna resonant frequency. As it may be noted, for the band at $13.5 \mathrm{GHz}$, Figure 5(a) shows that the most current mainly flows on the printed Tshaped dipole and this contributes that the most radiation is mainly due to this element. For the second band at $30 \mathrm{GHz}$, 


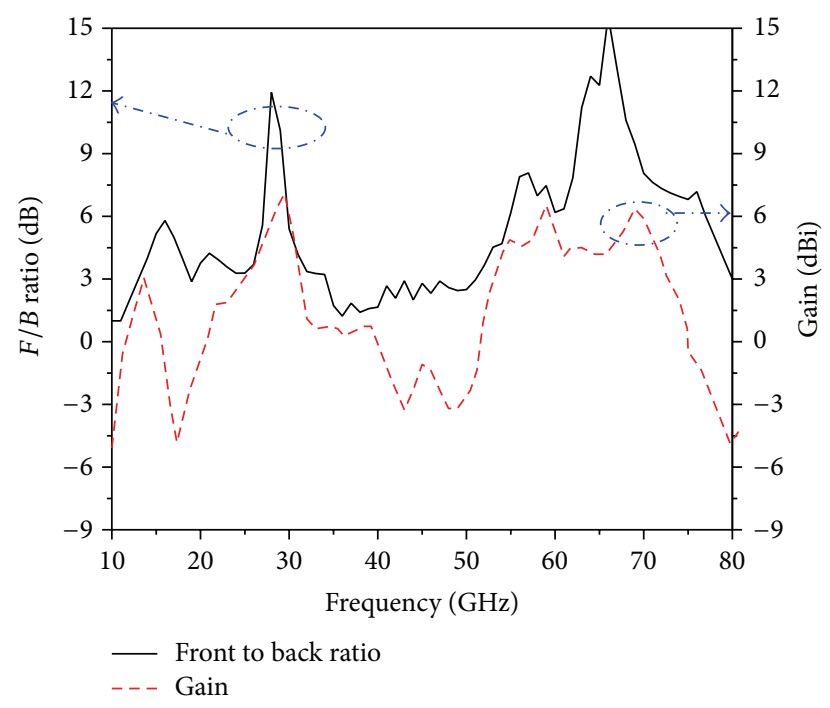

FIGURE 6: Simulated front to back ratio and gain of the proposed antenna.

Figure 5(b) shows that the current is mainly concentrated on the folded dipole, and this contributes the most radiation in this band. The same happens for the third band at $60 \mathrm{GHz}$, where current mainly concentrates on the parasitic element. As may be seen from Figure 6, simulated radiation profile (front to back ratio) is about $4.5 \mathrm{~dB}, 9 \mathrm{~dB}$, and $7 \mathrm{~dB}$ while the simulated antenna gain is about $2.9 \mathrm{dBi}, 7 \mathrm{dBi}$, and $6 \mathrm{dBi}$, at 13.5 GHz, $30 \mathrm{GHz}$, and $60 \mathrm{GHz}$.

\section{Experimental Results and Discussion}

The antenna was fabricated using mechanical etching technology with $0.1 \mathrm{~mm}$ accuracy on Rogers RO3035 substrate with a 0.13 and $0.017 \mathrm{~mm}$ dielectric and copper thickness. End launcher connector $1.85 \mathrm{~mm}$ is connected and an Anritsu 37397C vector network analyzer is used to measure the proposed antenna as shown in Figure 7(a). Comparison between measured and simulated reflection coefficient results is shown in Figure 7(b) with 5\%, 10\%, and 30\% impedance bandwidth at 13.5, 30, and $60 \mathrm{GHz}$, respectively. As it may be seen, the $\left|S_{11}\right|$ bandwidth $<-10 \mathrm{~dB}$ is almost the same between simulation and measurement, at lower frequencies, while at higher frequencies, the bands were shifted to lower frequency by about $3 \mathrm{GHz}$. This difference may be due to the capacitor loading between the proposed antenna and the fedconnector and may also be due to fabrication tolerance. The measured results were ended at $65 \mathrm{GHz}$ due to the limited range of the VNA. The gain characteristics of the proposed $\mathrm{mm}$ wave antenna are evaluated by using method presented in [16-18]. The gain of the antenna under test is calculated by using Friis transmission:

$$
\frac{\left|S_{21}\right|^{2}}{\left(1-\left|S_{11}\right|^{2}\right)\left(1-\left|S_{22}\right|^{2}\right)}=G_{t} G_{r}\left(\frac{\lambda}{4 \pi R}\right)^{2}
$$

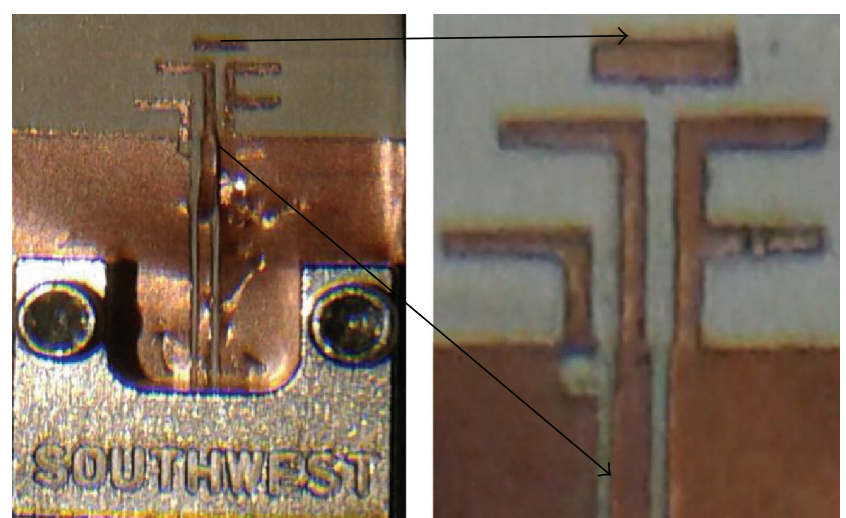

(a)

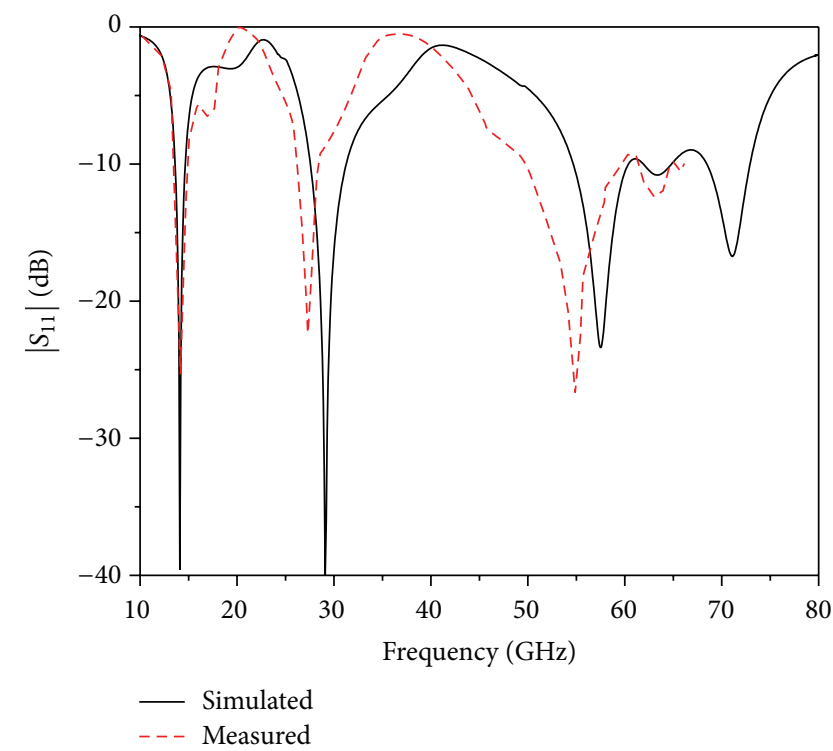

(b)

Figure 7: (a) Photo of fabricated antenna and (b) simulated and measured $\left|S_{11}\right|$ characteristics of the antenna.

where $G_{t}, G_{r}$ are the gains of the transmitting and receiving antennas, respectively, while $\left|S_{21}\right|,\left|S_{11}\right|$, and $\left|S_{22}\right|$ are the transmission and reflection coefficient between a reference horn antenna having a known gain (Quin $\mathrm{Star} \approx 21 \mathrm{dBi}$ ) and the reflection coefficient of the proposed antenna, respectively. $\lambda$ is the operating wavelength and $R$ the distance between the two antennas.

The measured and simulated radiation patterns and peak gain of the proposed antenna at frequencies $13.5 \mathrm{GHz}$, $30 \mathrm{GHz}$, and $60 \mathrm{GHz}$ in the $X Z$ and $X Y$ planes are shown in Table 2. This table also shows the fair agreement of measured and simulated patterns and gain. Discrepancy may be due to the reflective bodies of automobiles that caused fluctuations in readings; the movement and positioning of the coaxial cable altered patterns and mis-mounting of the antennas caused altered patterns. These errors increased especially at high frequencies. The large cross polarization radiation is assumed to be generated by the balun and the use of the large connector. 
TABle 2: Radiation patterns, EM: black lines, measurements: red lines, $E_{\Phi}$ : solid lines, and $E_{\Theta}$ : dash lines. Axis is shown in Figure 1.

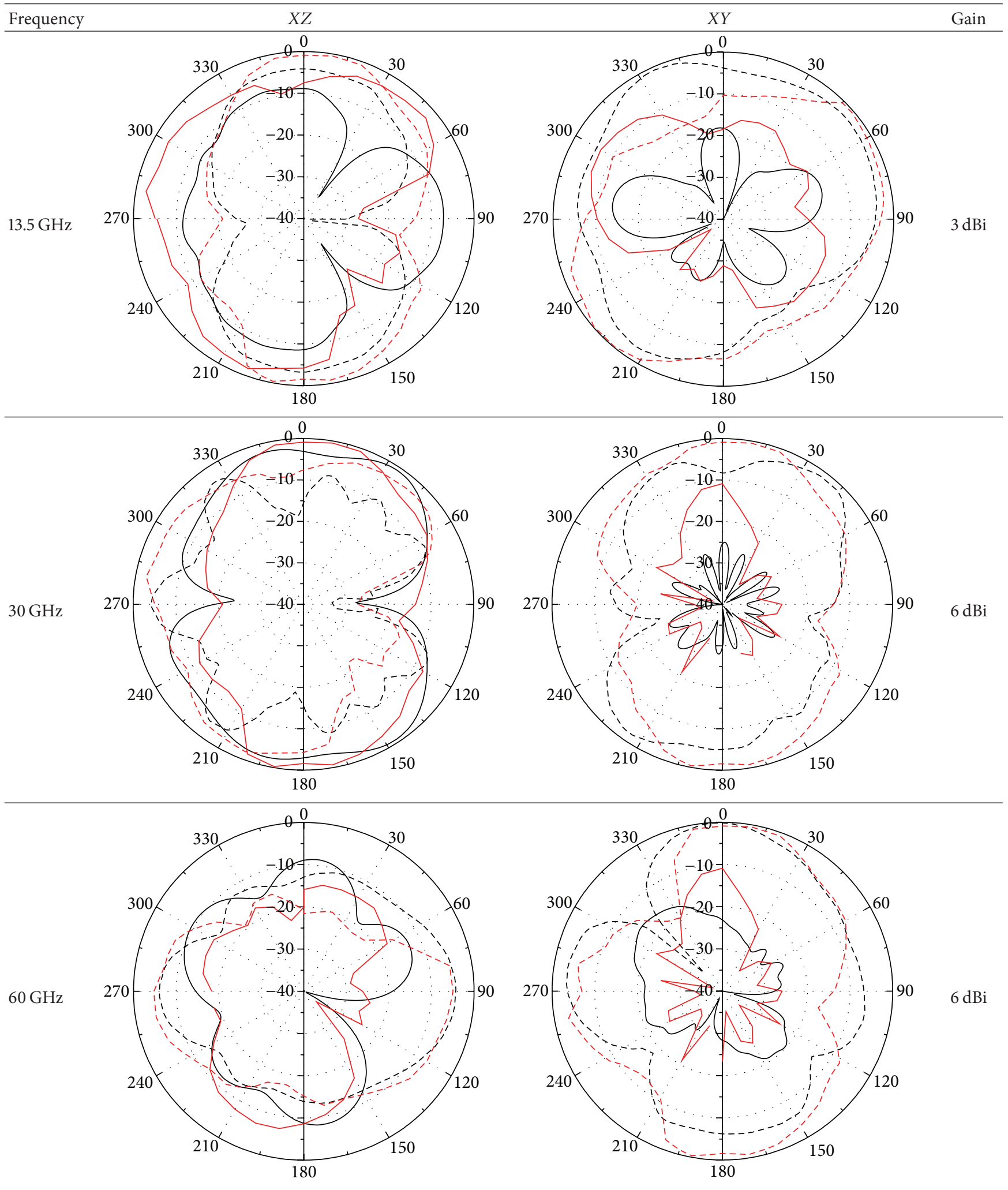




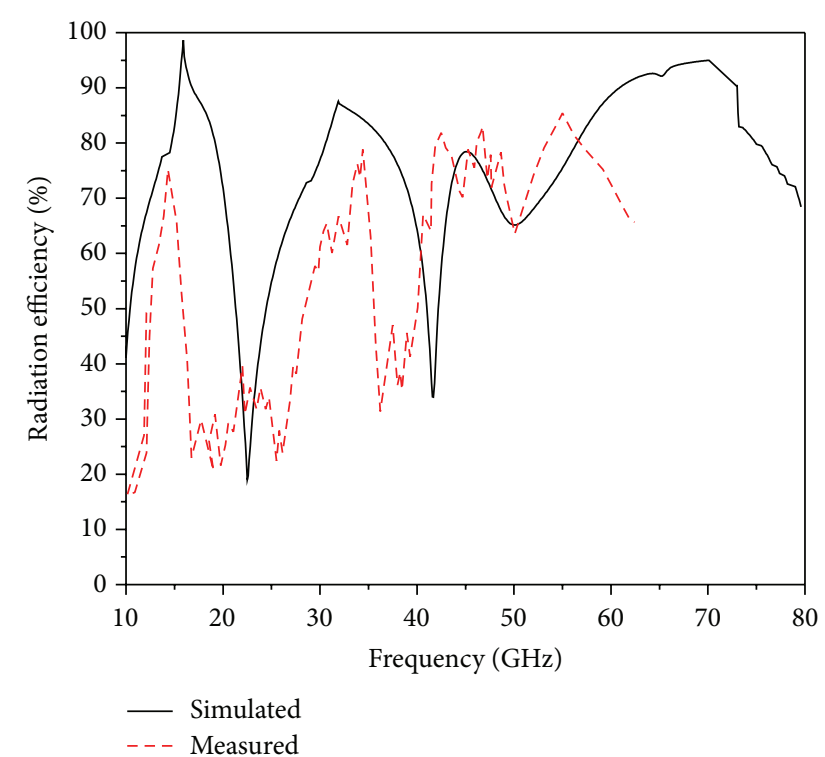

FIGURE 8: The proposed antenna radiation efficiency versus frequency.

The antenna radiation efficiency was measured using the Wheeler cap method [19-21] at different operating resonant frequencies as shown in Figure 8 . Results indicate that the larger end launcher connector comes on the expense of the radiation efficiency, which is reduced by $20 \%$ at the different operating frequencies. The radiation efficiency is almost $60 \%$ over the operating bands.

\section{Conclusion}

A new quasi-Yagi shaped antenna with multiband, circularly polarized, low profile, and low cost is presented. This antenna is particularly useful for satellite communications applications and short range wireless communications applications (WLAN/WPAN). The proposed antenna operates at three different bands $13.5 \mathrm{GHz}, 30 \mathrm{GHz}$, and $60 \mathrm{GHz}$ with $5 \%, 10 \%$, and $30 \%$ impedance bandwidth, respectively. The reflection coefficient is better than $-10 \mathrm{~dB}$ in the three bands and good agreement between measured and simulated gain and radiation pattern results were obtained. The front to back ratio is $6 \mathrm{~dB}$ with average gain of about $4 \mathrm{dBi}$ and the average antenna radiation efficiency is about $60 \%$ over the antenna operating band. The $3 \mathrm{~dB}$ axial ratio is achieved at the three selected bands.

\section{Conflict of Interests}

The authors declare that there is no conflict of interests regarding the publication of this paper.

\section{References}

[1] S. Trinh-Van, H. B. Kim, G. Kwon, and K. C. Hwang, "Circularly polarized spidron fractal slot antenna arrays for broadband satellite communications in Ku-band," Progress in Electromagnetics Research, vol. 137, pp. 203-218, 2013.

[2] K. Pítra and Z. Raida, "Planar millimeter-wave antennas: a comparative study," Radioengineering, vol. 20, no. 1, pp. 263-269, 2011.

[3] Y. Qian and T. Itoh, "A broadband uniplanar microstrip-toCPS transition," in Proceedings of the Asia-Pacific Microwave Conference (APMC '97), vol. 2, pp. 609-612, IEEE, December 1997.

[4] F.-J. Huang, C.-M. Lee, C.-Y. Kuo, and C.-H. Luo, "MMW antenna in IPD process for 60-GHz WPAN applications," IEEE Antennas and Wireless Propagation Letters, vol. 10, pp. 565-568, 2011.

[5] M. Sun and Y. P. Zhang, "100-GHz Quasi-Yagi antenna in silicon technology," IEEE Electron Device Letters, vol. 28, no. 5, pp. 455457, 2007.

[6] P. R. Grajek, B. Schoenlinner, and G. M. Rebeiz, "A 24$\mathrm{GHz}$ high-gain Yagi-uda antenna array," IEEE Transactions on Antennas and Propagation, vol. 52, no. 5, pp. 1257-1261, 2004.

[7] S. Beer, G. Adamiuk, and T. Zwick, "Novel antenna concept for compact millimeter-wave automotive radar sensors," IEEE Antennas and Wireless Propagation Letters, vol. 8, pp. 771-774, 2009.

[8] H. K. Kan, R. B. Waterhouse, A. M. Abbosh, and M. E. Bialkowski, "Simple broadband planar CPW-fed quasi-Yagi antenna," IEEE Antennas and Wireless Propagation Letters, vol. 6, pp. 18-20, 2007.

[9] H. Uchimura, N. Shino, and K. Miyazato, "Novel circular polarized antenna array substrates for $60 \mathrm{GHz}$-band," in Proceedings of the IEEE MTT-S International Microwave Symposium Digest, pp. 1875-1878, Long Beach, Calif, USA, June 2005.

[10] M. Fakharzadeh and M. Mohajer, "An integrated wide-band circularly polarized antenna for millimeter-wave applications," IEEE Transactions on Antennas and Propagation, vol. 62, no. 2, pp. 925-929, 2014.

[11] A. Ghobadi and M. Dehmollaian, "A printed circularly polarized Y-shaped monopole antenna," IEEE Antennas and Wireless Propagation Letters, vol. 11, pp. 22-25, 2012.

[12] X. L. Bao and M. J. Ammann, "A printed dipole antenna for wideband circular polarization operation," in Proceedings of the 3rd European Conference on Antennas and Propagation (EuCAP '09), pp. 2367-2370, March 2009.

[13] S.-S. Hsu, K.-C. Wei, C.-Y. Hsu, and H. Ru-Chuang, "A 60 GHz millimeter-wave CPW-fed Yagi antenna fabricated by using 0.18- $\mu$ CMOS technology," IEEE Electron Device Letters, vol. 29, no. 6, pp. 625-627, 2008.

[14] H. R. Chuang, L. K. Yeh, P. C. Kuo, K. H. Tsai, and H. L. Yue, "A $60 \mathrm{GHz}$ millimeter-wave CMOS integrated on-chip antenna and bandpass filter," IEEE Transactions on Electron Devices, vol. 58, no. 7, pp. 1837-1845, 2011.

[15] C.-H. Lin, G.-Y. Chen, J.-S. Sun, K.-K. Tiong, and Y. D. Chen, "The planar V-dipole antenna fed by marchand balun," in Proceedings of the Progress in Electromagnetics Research Symposium (PIERS '08), pp. 192-194, Hangzhou, China, March 2008.

[16] T. Fukasawa, T. Yanagi, H. Miyashita, and Y. Konishi, "Extended S-parameter method including radiation pattern measurements of an antenna," IEEE Transactions on Antennas and Propagation, vol. 60, no. 12, pp. 5645-5653, 2012.

[17] O. Staub, J. F. Zürcher, and A. Skrivervik, "Some considerations on the correct measurement of the gain and bandwidth of electrically small antennas," Microwave and Optical Technology Letters, vol. 17, no. 3, pp. 156-160, 1998. 
[18] D. Titz, M. Kyrö, C. Luxey, F. B. Abdeljelil, G. Jacquemod, and P. Vainikainen, "Radiation pattern measurement set-up for $60 \mathrm{GHz}$ on-chip antennas," in Proceedings of the 6th Loughborough Antennas \& Propagation Conference (LAPC '10), pp. 533536, IEEE, Loughborough, UK, November 2010.

[19] R. H. Johnston and J. G. McRory, "An improved small antenna radiation efficiency measurement method," IEEE Antennas and Propagation Magazine, vol. 40, no. 5, pp. 40-47, 1998.

[20] A. P. Raiva and J. Fabrega-Sanchez, "A rectangular cavity for cell phone antenna efficiency measurement," in Proceedings of the IEEE Antennas and Propagation Society International Symposium, pp. 740-743, July 2005.

[21] D. M. Pozar and B. Kaufman, "Comparison of three methods for the measurement of printed antenna efficiency," IEEE Transactions on Antennas and Propagation, vol. 36, no. 1, pp. 136-139, 1988.

[22] H. G. Schantz, "Radiation efficiency of UWB antennas," in Proceedings of the IEEE Conference on Ultra Wideband Systems and Technologies (UWBST '02), pp. 351-355, Baltimore, Md, USA, May 2002.

[23] J. An, G.-M. Wang, C.-X. Zhang, and H.-Y. Zeng, "A compact, omni-directional, circularly polarized microstrip antenna," Microwave Journal, vol. 53, no. 1, pp. 82-90, 2010. 

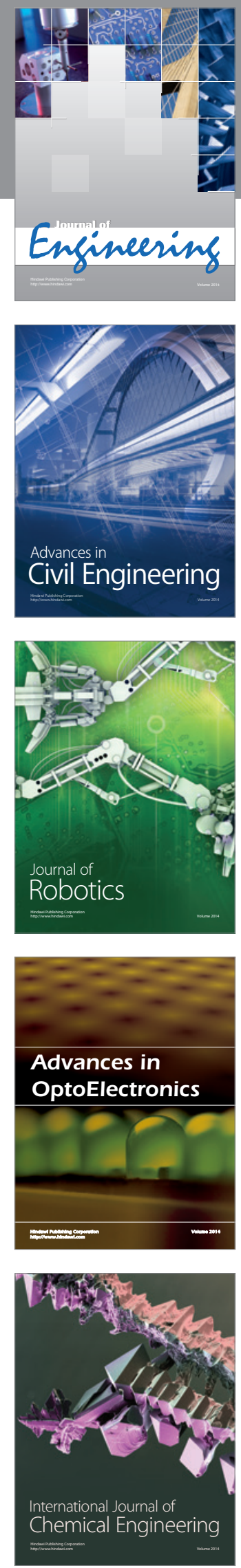

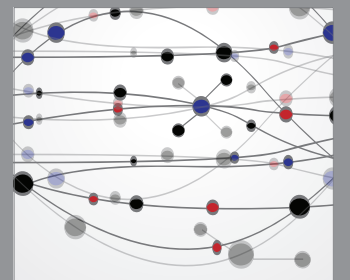

The Scientific World Journal
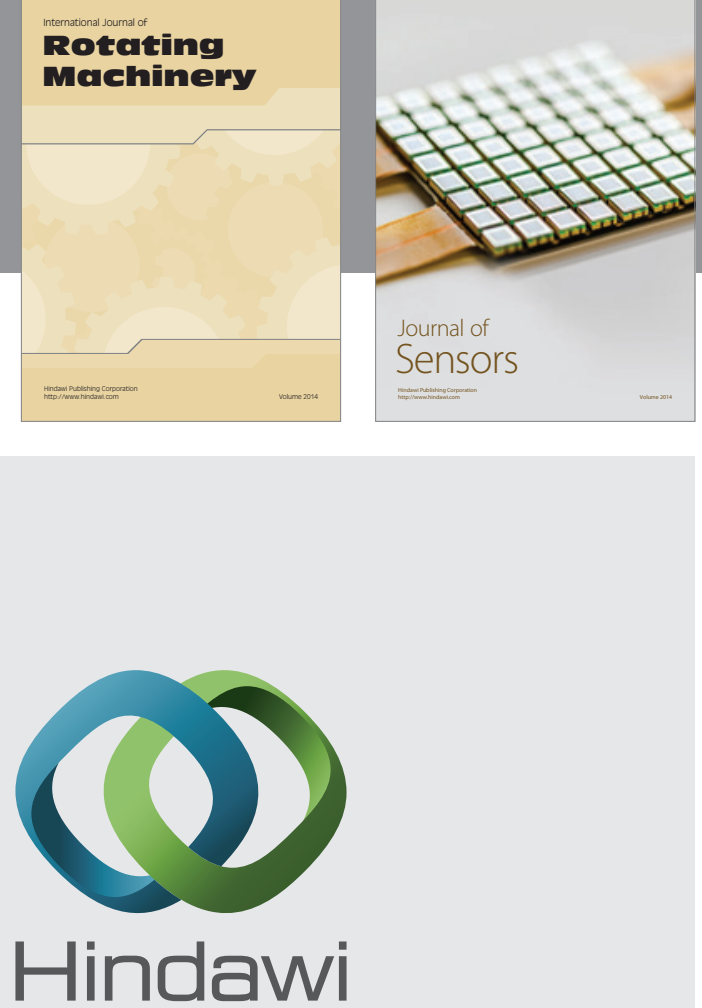

Submit your manuscripts at http://www.hindawi.com
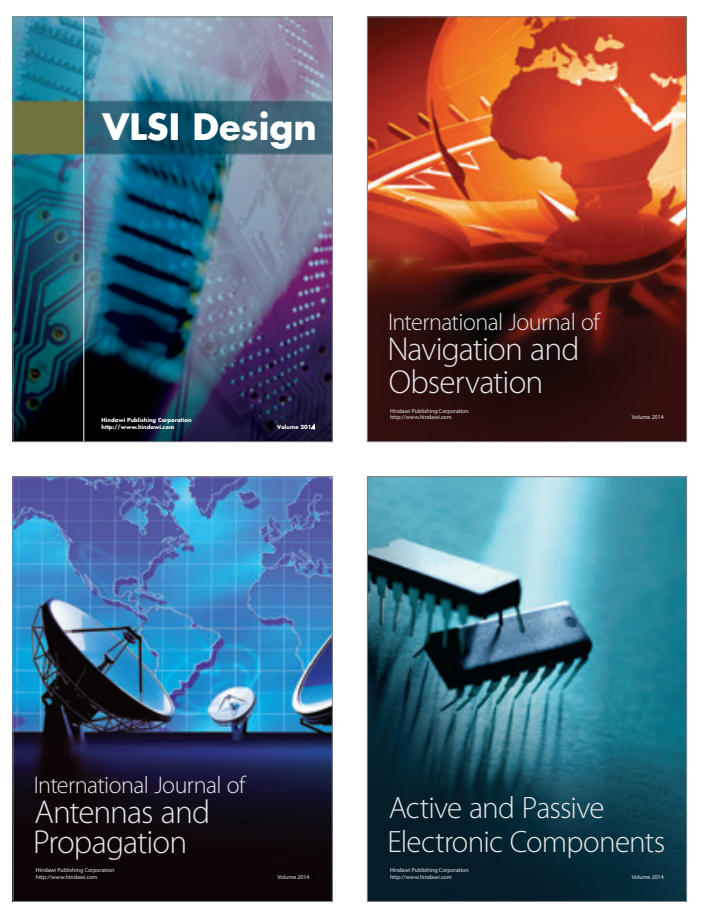
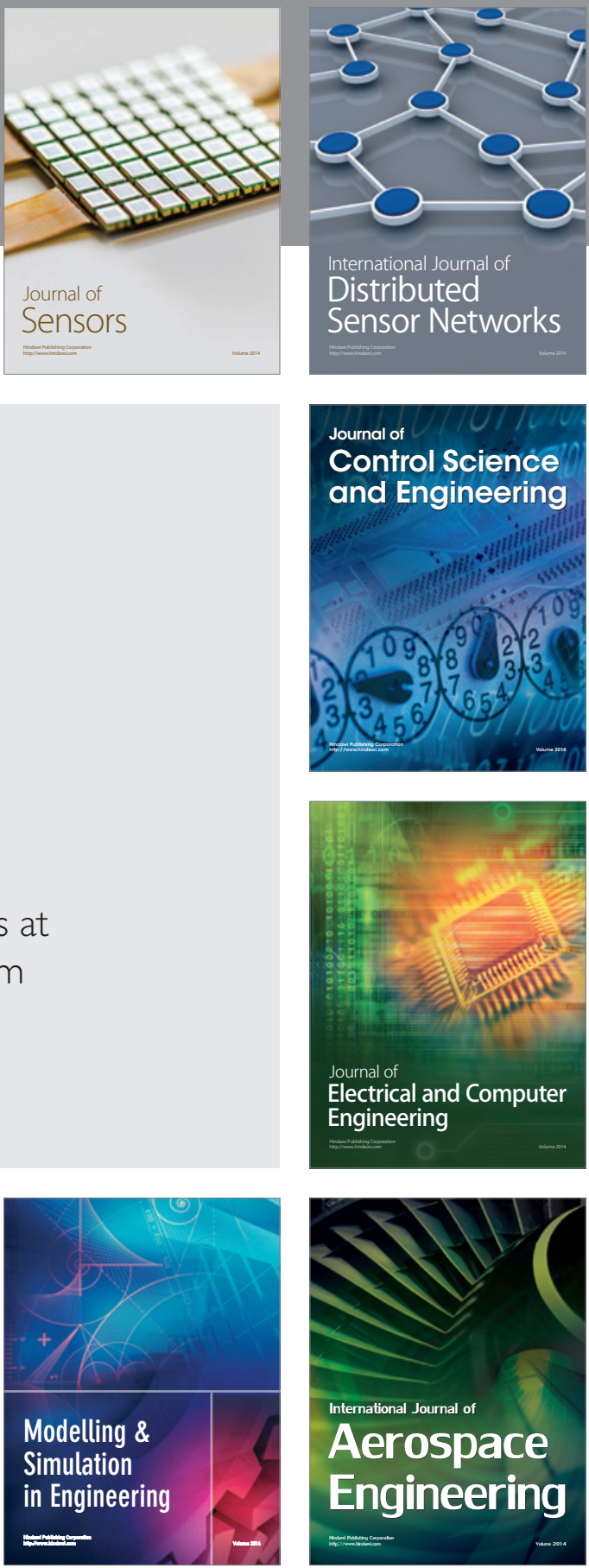

Journal of

Control Science

and Engineering
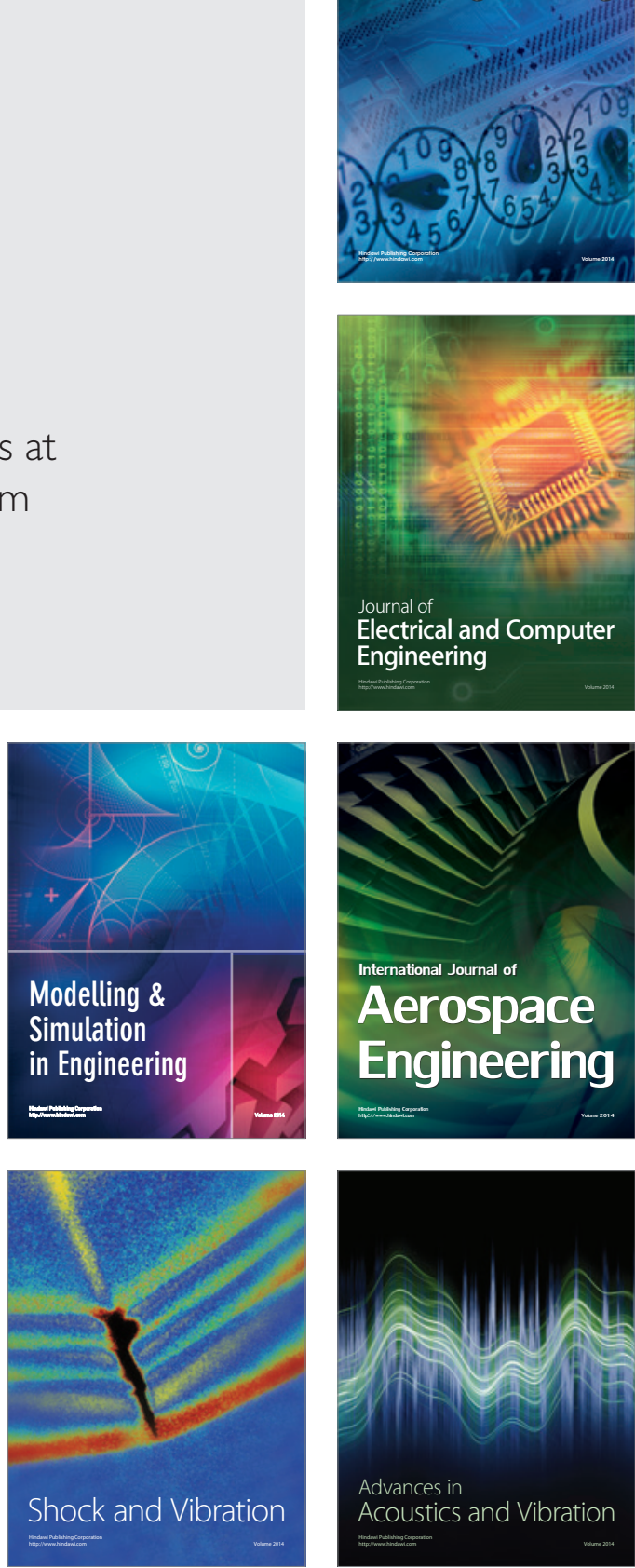